\section{REDE SOCIOTÉCNICA DO NÚCLEO DE AGROECOLOGIAAPETÊ CAAPUÃ DE SOROCABA (SP:) PERCEPÇÕES E AVALIAÇÃO DAS AÇÕES DESENVOLVIDAS NO CONTEXTO DAS POLÍTICAS PÚBLICAS}

Caio Yamazaki Saravalle Lucimar Santiago de Abreu

Resumo: Apesar da atual importância da problemática relacionada às redes sociotécnicas e o fortalecimento de núcleos de agroecologia, até o momento essa temática foi pouco estudada. A pesquisa teve como objetivos: i) caracterizar o universo social da rede sociotécnica do Núcleo Apetê Caapuã da UFSCar (SP); ii) avaliar, por meio das percepções do grupo as políticas públicas de incentivo à agroecologia, em especial dos Núcleos de Estudos em Agroecologia (NEA). Para tanto, realizou-se entrevistas semiestruturadas, aplicação de questionário online e observação participante em reuniões chaves do grupo. Foram sistematizados os projetos desenvolvidos pelo grupo a partir dos editais CNPq, PET, PROEXT e ProEx, além da identificação das percepções dos sujeitos envolvidos, que expressam a importância dos mesmos nas atividades de ATER e construção do conhecimento agroecológico pelo grupo. Conclui-se que apenas os editais de NEAs não são suficientes para a manutenção do Núcleo, sendo importante a articulação entre as políticas como o PET, PRONERA, Editais CNPq e, outros órgãos para a sustentabilidade da rede. Os principais desafios apontados são a falta de tempo suficiente dos projetos para a transição agroecológica das unidades de produção familiar, além da pouca disponibilidade de recursos para a contratação de profissionais formados em ATER.

Palavras-chave: Políticas Públicas; Extensão Rural; Extensão Universitária.

Programa de Pós-Graduação em Agroecologia e Desenvolvimento Rural - PPGADR, Centro de Ciências Agrárias - Universidade Federal de São Carlos - UFSCar; caio.sarava@gmail.com

2EMBRAPA Meio Ambiente; lucimar.abreu@embrapa.br
Abstract: Despite the current importance of the problem related to sociotechnical networks and the strengthening of agroecology nuclei, until now this theme has been little studied. The objective of the research was to: $i$. characterize the social universe of the socio-technical network of the Apetê Caapuã Nucleus of UFSCar (SP); ii. to evaluate, through the perceptions of the group, the public policies of incentive to agroecology, in particular of the Nuclei of Studies in Agroecology (NEA). For that, we conducted semistructured interviews, application of online questionnaire and participant observation in key group meetings. The projects developed by the group from the CNPq, PET, PROEXT and ProEx edits were systematized, as well as the identification of the perceptions of the subjects involved, which express their importance in the activities of ATER and the construction of agroecological knowledge by the group. It is concluded that only the calls for NEAs are not sufficient for the maintenance of the Nucleus, being important the articulation between the policies, like the PET, PRONERA, CNPq calls, among others, for the sustainability of the network. The main challenges are the lack of sufficient time for the projects for the agroecological transition of the family production units, as well as the limited availability of resources for the contracting of professionals trained in ATER.

Keywords: Public Policies, Rural Extension, University Extension

\section{Introdução}

Nos últimos anos cresceu o interesse por estudos relacionados à agroecologia que não sejam focados apenas na perspectiva agronômica ou ecológica, mas ainda são poucos os estudos que tratam a questão da emergência novas configurações de redes, mais especificamente denominada redes sociotécnicas (ABRAMOVAY, 2000) de agroecologia. O olhar das ciências sociais traz grandes contribuições para a compreensão do funcionamento e papel das redes sociotécnicas de agroecologia e para o entendimento da sua relação com as políticas públicas, proporcionando uma reflexão qualificada. Essa problemática de pesquisa é parte integral da abordagem da investigação que visa captar as percepções dos atores sociais, as relações que estabelecem com o mundo rural, os sujeitos protagonistas dos movimentos sociais e as múltiplas facetas do desenvolvimento rural no mundo contemporâneo.

Neste sentido, é de grande importância os estudos que buscam 
compreender quem são e o que pensam estes atores e, como diversos elemento da dimensão sociocultural e econômica influenciam suas ações (ABREU, 2005). Portanto, neste tipo de pesquisa sobre o mundo rural contemporâneo selecionou-se como público alvo da pesquisa não mais simplesmente agricultores ou técnicos, mas o conjunto de atores vinculados aos coletivos articulados com projetos de fomento à agroecologia.

Esses projetos, em geral, são aprovados para terem sua execução por Núcleos de Estudos em Agroecologia (NEA). Essas iniciativas de suporte ocorrem por meio de editais públicos do CNPq (Conselho Nacional de Desenvolvimento Científico e Tecnológico). As iniciativas de fomento ao desenvolvimento da agroecologia são tidas como fundamentais para o fortalecimento das ações de transição para uma agricultura de base ecológica, uma vez que as ações são operacionalizadas diretamente junto aos agricultores familiares e jovens rurais, trata-se de ações afirmativas que visam dar visibilidade e reconhecer saberes e conhecimentos de natureza ecológicos, base das ações de um conjunto de agricultores familiares do país, incluindo a valorização da cultura local. Pode ser a base para as mudanças necessárias com inclusão social, e reforça positivamente as identidades locais e a relação entre campo e cidade. No corpo desta proposição afirmam o compromisso com as diversidades de atores locais e cidadania ativa, pois permitem a continuidade de uma política social e ecológica. Essas ações afirmativas são parte de um processo mais amplo da transição da agricultura de base ecológica, podendo ser consideradas um pressuposto para um amplo conjunto de mudanças.

Assim, o presente artigo tem como objetivo principal, avaliar as políticas públicas vinculadas à construção do conhecimento agroecológico, em específico as chamadas relacionadas aos Núcleos de Estudos em Agroecologia, por meio do estudo de caso do Núcleo de Agroecologia Apetê Caapuã, contribuindo para o aperfeiçoamento e ampliação das chamadas públicas de Agroecologia.

Buscando atender esse objetivo foram desenvolvidos, por meio de uma abordagem qualitativa e participativa, uma caracterização do universo social da rede sociotécnica do Núcleo Apetê Caapuã da UFSCar Sorocaba (SP); a descrição das ações dessa rede como resultado das políticas públicas e projetos acessados; descrição das percepções dos membros sobre as ações desenvolvidas. Para captar a visão dos atores a respeito dos projetos e políticas públicas de agroecologia utilizou-se o aporte teórico sobre percepções (ABREU, 2005; RODRIGUES, et.al., p. 99, 2012). Foram realizadas entrevistas semiestruturadas com os membros atuais e anteriores do grupo, de modo a resgatar o histórico das atividades desenvolvidas, bem como a aplicação de questionários online sobre suas trajetórias, motivações, referenciais e percepções. Ademais, foram coletados dados secundários por meio de revisão bibliográfica e dados primários junto aos membros sobre os projetos desenvolvidos no âmbito das políticas públicas.

O trabalho está dividido em quatro seções: primeiramente apresentamos uma breve introdução. A segunda seção busca, por meio de uma revisão da literatura e exploração de dados secundários, apresentar os conceitos abordados e descrever o contexto em que se insere a pesquisa, introduzindo o desenvolvimento da agroecologia no Brasil, para em seguida focar no surgimento dos Núcleos de Estudos em Agroecologia e o papel da juventude neste processo. Além disso, contextualiza e descreve as políticas públicas voltadas para este público específico. Na seção seguinte, dedicase ao percurso metodológico adotado na pesquisa. Por fim, apresenta-se os resultados e breves considerações finais.

\section{Revisão da literatura}

A seguir, apresenta-se uma revisão da literatura sobre os principais conceitos utilizados na pesquisa, bem como o processo histórico do desenvolvimento da agroecologia no Brasil, especialmente o surgimento dos Núcleos de Estudos em Agroecologia.

\section{Redes sociotécnicas}

O conceito de rede vem sendo muito utilizado nas ciências sociais e nos estudos relacionados ao desenvolvimento rural nas últimas décadas. Autores como Radcliffe-Brown (1952) e Castells (2003) argumentam que a dinâmica da rede, com suas características de interconexões e fluxos estariam na base fundante de nossa nova morfologia social. Para Radcliffe-Brown(1952), nossa sociedade seria baseada na rede de relações sociais existentes, sustentadas a partir da confluência de interesses ou no manejo dos conflitos resultantes.

A imagem da rede é uma metáfora potente (uma trama de fluxos de relações entre nós), sendo utilizada em diversos contextos distintos, desde a Administração até a Tecnologia da Informação, mas de modo geral, a rede representa uma forma de organização ou prática social.

Segundo Abramovay (2000), revisitando as concepções de Latour (1995), 
as redes sociotécnicas são aquelas que são compostas por um conjunto de especialistas ou técnicos, mas também por elementos não-humanos, conferindo seu caráter heterogêneo e altamente imprevisível quanto às articulações que as compõe. Deste modo, os nós podem ser constituídos por atores sociais, grupos de pessoas, instituições, tecnologias, objetos, entre outros, sendo que cada rede possui uma composição específica. Outro elemento importante é uma nova percepção da dimensão espacial, sendo não mais uma moldura das ações sociais, mas um espaço político que extrapola fronteiras, onde a realidade se apresenta por meio das relações estabelecidas.

Neste contexto, escolheu-se o conceito de rede sociotécnica como definição e perspectiva analítica do Núcleo de Agroecologia Apetê Caapuã, pois compreende-se que a abrangência do núcleo extrapola os limites territoriais e de composição exclusiva de seus membros. Sendo assim, o Núcleo pode ser representado como uma teia de relações interdependentes. Neste sentido, buscou-se determinar quais são os nós constituintes desta rede e o papel que as políticas públicas assumem na confecção dos fios de relações desta teia.

\section{A importância da percepção na pesquisa qualitativa de natureza} participativa

Levando em consideração a percepção dos atores e sujeitos da pesquisa, inúmeros trabalhos têm se focado nos distintos sentidos do conceito de percepção e como ele pode ser considerado no incentivo à incorporação dos conhecimentos locais nas pesquisas cientificas.

Portanto, segue uma breve construção histórica sobre a percepção.

Os estudos da percepção humana têm início no final do século XIX com os estudos do psicólogo Wilhelm Wundt (1832-1920) em seu laboratório experimental com foco nos estudos da percepção (SIMÕES; TIEDEMANN, 1985), norteando a formação das escolas e teorias que aprofundaram o conceito (RODRIGUES, et al., p. 99, 2012).

Dentre as linhas conceituais da percepção, descreve-se a seguir a Fenomenologia e o Behaviorismo Radical, estudos que se distinguem em significado, mas que são importantes para a construção conceitual da percepção e também para a formatação de metodologias cientificas, com enfoque cultural e social.

Merleau Ponty resume a concepção de comportamento à consciência perceptiva, na qual teorias do comportamento e da percepção estão inteiramente interligados, existindo uma reciprocidade (RODRIGUES, et.al., p. 99, 2012). Portanto, a percepção é fundamental em estudos das funções sociais, pois considera a vivência de cada elemento com o fenômeno abordado. Para Abreu, 2005, a percepção dos agentes é fruto de interação de valores, condições sociais e oportunidades econômicas. Portanto são múltiplas, é necessário considerar esses elementos para desvendá-las.

Apesar das diferentes definições encontradas na literatura, pode-se identificar que para ambas as vertentes a percepção é uma consciência intencional que está intimamente relacionada ao comportamento que os indivíduos tomam perante suas realidades, sendo extremamente complexo já que perpassa o comportamento perceptivo.

Por fim, trabalhos recentes iniciados na década de 1960, apontam a importância da percepção também nos estudos na área do meio ambiente, principalmente relacionados à geografia. A proposta é de que a percepção seja utilizada não apenas na elucidação da relação entre homem e ambiente, mas também nas pesquisas sociais ou políticas (PACHECO; SILVA, 2006).

No desenvolvimento da pesquisa é necessário compreender de que maneira os valores presentes resultam em percepções distintas do mesmo fenômeno, mesmo por indivíduos constituintes de um mesmo grupo social (MELLAZO, 2005; RIBEIRO, 2003; SIMÕES; TIEDEMANN, 1985; OKAMOTO, 2002; RODRIGUES, 2012). (RODRIGUES, et al, p. 101, 2012).

Portanto, a percepção é um componente importante nos estudos que buscam incorporar a visão dos atores e sujeitos envolvidos com a pesquisa, de modo a agregar suas vivências e experiências em uma análise participativa da realidade estudada.

\section{Histórico da Agroecologia no Brasil e os Núcleos de Estudos em} Agroecologia (NEA)

No final da década de 1970, surgem os primeiros e mais significativos trabalhos que lançam os fundamentos do que iria se tornar a atual agroecologia. Em 1989, Miguel Altieri publica o livro "Agroecologia: as bases científicas da agricultura alternativa" focando a análise política e social na construção da dependência dos camponeses ao modelo de desenvolvimento capitalista, bem como suas estratégias de resistência via desenvolvimento de técnicas agronômicas apropriadas, economicamente e ambientalmente sustentáveis. Outro pioneiro, Stephen Gliessman (2000) preconiza a "aplicação de conceitos e princípios ecológicos no desenho e 
manejo de agroecossistemas sustentáveis". Sendo assim, sua contribuição principal representa a aproximação da Ecologia à Agronomia, buscando um equilíbrio ecológico na produção primária.

No Brasil, a agroecologia tem início com os debates na década de 1980 dos Encontros Brasileiros de Agricultura Alternativa (EBAA), motivados pela conjuntura da época, em que o avanço das políticas econômicas de industrialização do campo ou a "modernização conservadora" termo cunhado por (GRAZIANO DA SILVA, 1982) da década de 1960 geravam o empobrecimento das populações rurais, a expropriação e o êxodo rural, além do esgotamento da fertilidade dos solos, a perda da biodiversidade de sementes e raças animais, envenenamento de ambientes e populações, no que se convencionou chamar de Revolução Verde.

Na década de 1990, houve a criação de diversas ONGs resultantes da atuação da PTA/FASE (Projeto de Tecnologias Alternativas/ Federação de Órgãos para a Assistências Social e Educacional, respectivamente), criando-se a Rede PTA e a AS-PTA (Assessoria e Serviços a Projetos em Agricultura Alternativa). É a partir desta reestruturação que o termo agroecologia é incorporado, influenciado pelos trabalhos de Miguel Altieri, dando embasamento à discussão do processo endógeno de desenvolvimento de tecnologias apropriadas pelos produtores e não uma mera transferência de técnicas, como preconizava a política pública de extensão rural promovida pelo governo da época (BENSADON, 2016).

A partir dos anos 2000, a agroecologia ganha corpo com a criação de entidades nacionais dispostas a desenvolver a agroecologia no campo científico e político, como a ANA (Articulação Nacional de Agroecologia) e a ABA-Agroecologia (Associação Brasileira de Agroecologia), resultando na articulação dos ENAs (Encontros Nacionais de Agroecologia) e CBA (Congresso Brasileiro de Agroecologia). AABA-Agroecologia integra a ANA enquanto entidade-membro da coordenação nacional, sendo um reconhecido ator de mobilização do campo científico-acadêmico (PETERSEN et al, 2009). Além disso, dentro das universidades organizavam-se os Grupos de Agroecologia (GA), em sua maioria originados nos cursos de Agronomia, Engenharia Florestal e em menor quantidade na Biologia, frequentemente vinculadas a Centros Acadêmicos. Atualmente, os grupos são cada vez mais diversificados, sendo constituídos por pessoas de outros campos acadêmicos e, inclusive, de fora da universidade. Em 2010 foi criada a REGA Brasil (Rede Brasileira de Grupos de Agroecologia) durante o II ENGA (Encontro
Nacional de Grupos de Agroecologia) em Aldeia Velha-RJ. O Encontro e a Rede inspiram-se em padrões horizontais e autogestionários de atuação, relação e organização social. Além disso, seus processos deliberativos são baseados na democracia direta (FURQUIM, 2014). No Brasil todo estão cadastrados aproximadamente 50 Grupos de Agroecologia. Somente na região Sudeste estão cadastrados 38 grupos, sendo 17 no estado de São Paulo (REGA BRASIL, 2016).

Muitos Grupos de Agroecologia são, também, Núcleos de Estudos em Agroecologia (NEA). Os núcleos foram criados a partir de 2010, por meio do Edital MDA/SAF/CNPq 058/2010 com o objetivo de qualificar a formação de professores, alunos e técnicos extensionistas, de modo a garantir serviços de assistência técnica e extensão rural (ATER) aos agricultores familiares, considerando os princípios e objetivos da Política Nacional de Assistência Técnica e Extensão Rural (Lei nº 12.188, de 11 de janeiro de 2010). Desde sua criação, foram apoiados 281 projetos em 102 instituições de ensino superior diferentes. Os núcleos estão distribuídos em todas as regiões políticas do país, com uma predominância na região Nordeste.

Apesar disto, o estado de Minas Gerais concentra a maior quantidade de municípios por unidade da federação, sendo criados 40 grupos em 22 municípios nos últimos 7 anos de política (Figura 1).

O Núcleo de Agroecologia Apêtê-Caapuã (NAAC), tem origem em 2009 no campus Sorocaba da UFSCar. Seu nome tem origem tupi-guarani, em que apetê significa um modo de cultivo agroflorestal em nucleação e caapuã, aquele ou aquilo que mora no mato. O grupo se define como um coletivo de iniciativa de alunos e professores para atuarem em Agroecologia junto a agricultores familiares e assentados da reforma agrária (ROSA et al, 2014). Tal concepção já denota a concepção de agroecologia que o grupo possui, aliado aos movimentos sociais de luta pela terra e da agricultura familiar.

A discussão em torno da agroecologia no campus iniciou-se em 2009 com a admissão do Prof. Dr. Fernando Silveira Franco como professor adjunto no curso de Engenharia Florestal, sendo especialista em Conservação de Recursos Naturais, principalmente nos temas sistemas agroflorestais, agroecologia, extensão rural e planejamento participativo. Formou-se um grupo de discussão de assuntos relacionados à agroecologia e trocas de experiências a partir do interesse de alunos do curso de engenharia florestal e ciências biológicas, sob orientação deste professor.

Os primeiros encontros contaram com um número pequeno de alunos 
Figura 1 - Municípios por unidade da federação com Núcleos de Estudos em Agroecologia. Fonte: apresentação oral Comissão Nacional de Educação em Agroecologia, II Seminário Nacional de Educação em Agroecologia, Seropédica-RJ, 2016.

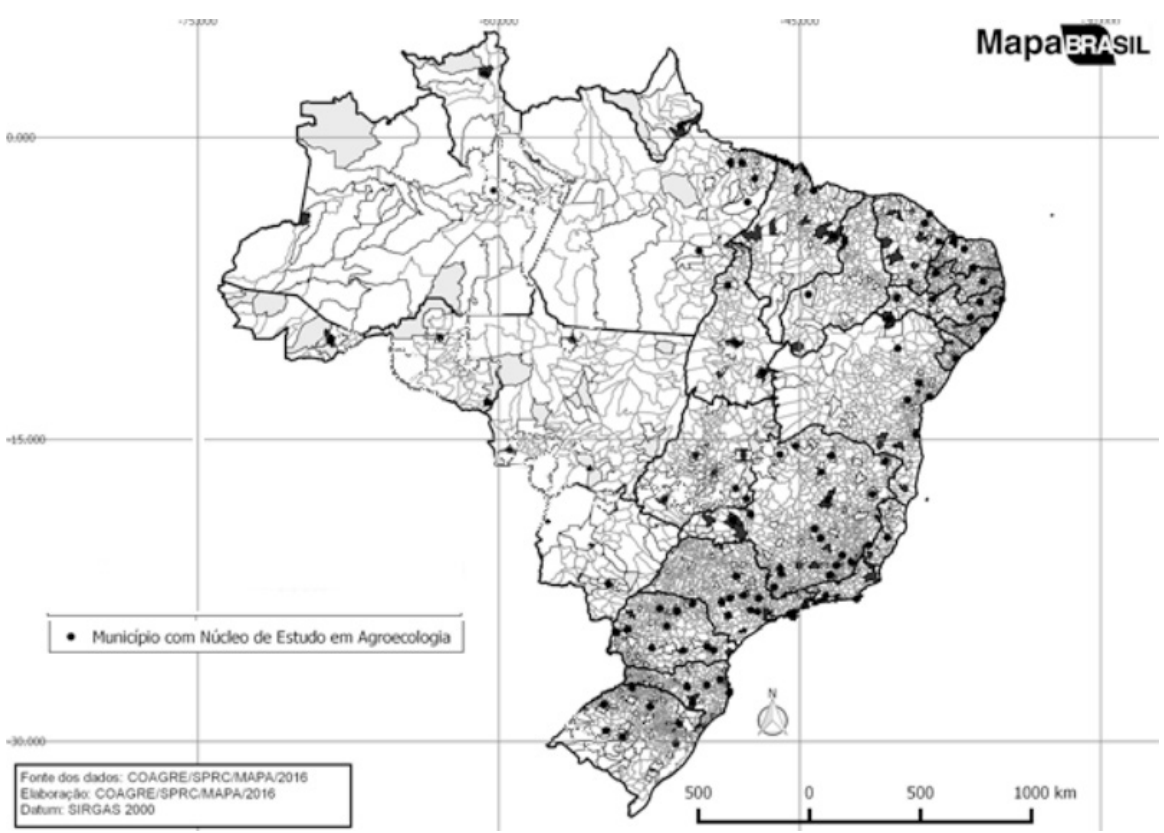

da universidade e se concentraram em leituras e discussões das estruturas básicas da agroecologia, desenvolvendo os conceitos básicos do grupo. A partir de então, as reuniões tornaram-se semanais, tendo início o planejamento da prática agroecológica dentro do campus para divulgar o início do grupo (ROSA et al, 2014).

Por meio de um projeto submetido à diretoria do campus, o Núcleo conquistou uma área de $3000 \mathrm{~m}^{2}$ para desenvolver experiências e elaborar práticas relacionadas à agroecologia.

Desde 2009 já acessava recursos para financiamento de suas ações por meio de editais da ProEx (Pró-Reitoria de Extensão da UFSCAR). No ano seguinte o grupo é contemplado nos editais do PROEXT do MEC, CNPq (Conselho Nacional de Desenvolvimento Científico e Tecnológico) e PET (Programa de Ensino Tutorial) que serão descritos detalhadamente posteriormente.

Apesar de o núcleo ser oficialmente um grupo PET, organiza-se de modo autogestionário, onde os alunos dividem responsabilidades na gestão junto ao professor tutor. Atualmente, o grupo divide-se em GTs (Grupos de Trabalho) e Gestão (Tabela 1), responsável pela divisão das atividades burocráticas. Obrigatoriamente, a partir de 2015, cada membro participa de um GT e de um grupo da Gestão.

Tabela 1 - Dinâmica de organização do Núcleo de Agroecologia Apetê Caapuã.

\begin{tabular}{ccc}
\hline GT (Grupo de Trabalho) & Gestão \\
\hline Comercialização/Feira & Celebração \\
\hline Integração Campo-Cidade & Comunicação \\
\hline Pesquisa e Grupos de Estudos & Financeiro \\
\hline Transição Agroecológica & Parcerias \\
\hline UEPA (Unidade de experimentação & Secretaria \\
Participativa Agroecológica) & \\
\hline
\end{tabular}

Fonte: dados da pesquisa, 2016.

Deste modo, todos os membros participam da manutenção do próprio núcleo, evidenciando uma concepção mais horizontalizada de organização, refletindo nas ações que o grupo desenvolve junto aos próprios agricultores.

\section{Metodologia}

De modo a identificar os componentes da rede sociotécnica e sistematizar a experiência prática do Núcleo de Agroecologia Apetê-Caapuã da UFSCar Sorocaba, contemplando as percepções de seus membros sobre o processo, utilizou-se técnicas de pesquisa qualitativa e participativa. Foram realizadas quatro entrevistas semiestruturadas, sendo uma com o professor coordenador do núcleo e três com membros atuais. Aplicouse questionários online a membros e ex-membros do Núcleo durante o segundo semestre de 2016, totalizando 18 questionários respondidos. Tanto o roteiro da entrevista, quanto os questionários continham questões que buscavam compreender o perfil dos membros, a identificação das principais atividades desenvolvidas pelo grupo e a percepção que tinham sobre as políticas públicas acessadas e a importância destas para as ações e para a agroecologia como um todo. Além disso, realizou-se a observação 
participante em diversas ocasiões de reuniões do grupo, totalizando três reuniões gerais ordinárias e uma oficina de sistematização de experiências promovida pela ABA (Associação Brasileira de Agroecologia) durante o mês de março de 2017 com o intuito de captar informações sobre a organização interna do grupo e a dinâmica de funcionamento em relação aos parceiros. Os dados foram sistematizados, usando técnicas da análise qualitativa através da descrição densa da experiência do núcleo articuladas com a análise das percepções desses atores sociais (ABREU, 2005). Procedeu-se, então, à descrição do universo social da rede sociotécnica do Núcleo e, por meio de dados secundários produzidos pelo próprio núcleo sobre sua avaliação e participação nos editais, bem como dados disponíveis nos sites do Ministério do Desenvolvimento Agrário, Ministério da Educação e UFSCar, uma descrição de todas as atividades desenvolvidas através das políticas públicas. Assim, buscou-se identificar as percepções dos atores ou membros do Núcleo que se constituem numa rede social.

Portanto, a pesquisa valeu-se da abordagem qualitativa e compreensiva das ciências sociais, sendo fundamental a participação do pesquisador em processos e dinâmica do grupo estudado para adentrar na compreensão da percepção dos sujeitos sobre sua ação.

\section{Resultados e Discussão}

Caracterização da Rede Sociotécnica do Núcleo de Agroecologia Apetê Caapuã

O Núcleo de Agroecologia Apetê Caapuã se reúne quinzenalmente, buscando resgatar as atividades desenvolvidas e planejar as ações futuras, realizando uma Celebração Inicial de Ano, onde é feito todo o planejamento do semestre por meio da metodologia "Dragon Dreaming", desenvolvida pelo australiano John Croft que busca o planejamento e realização de projetos criativos e sustentáveis que leva em consideração os sonhos e anseios dos indivíduos. É divido em quatro fases: sonho, planejamento, realização e celebração.

O Núcleo possui, atualmente, 33 membros, sendo que 12 são bolsistas PET e os demais são colaboradores voluntários ou externos, como alunos e ex-alunos da UFSCar, tanto de graduação, quanto de pós-graduação. Além disso, conta com o apoio de profissionais da área ambiental e de ATER da região de Sorocaba e de outras partes do estado. O quadro abaixo (Tabela 2) apresenta a composição atual do grupo.
Tabela 2 - Composição atual dos membros bolsistas do Núcleo de Agroecologia Apete Caapuã.

\begin{tabular}{cc}
\hline \multicolumn{1}{c}{ Curso/Formação } & Número de membros \\
\hline $\begin{array}{l}\text { Licenciatura e Bacharel em } \\
\text { Ciências Biológicas }\end{array}$ & 06 \\
\hline Engenharia Florestal & 05 \\
\hline Geografia & 01 \\
\hline \multicolumn{2}{c}{ Fonte: dados da pesquisa, 2016. }
\end{tabular}

A presença maciça de estudantes de Biologia não surpreende se nos atentarmos à história do grupo. $\mathrm{O}$ grupo surge após a ida de um grupo de estudantes de Biologia ao EREB-SE (Encontros de Estudantes de Biologia do Sudeste) na UNESP Botucatu em 2009. Ao retornarem, propõe junto ao prof. Fernando a organização de uma oficina de bioconstrução do espaço do Centro Acadêmico "Lobo Guará". A partir de então, surge o grupo de estudos em Agroecologia que se tornaria o Apetê-Caapuã.

Atualmente, o grupo passou por uma grande renovação de membros, já que houve uma nova seleção de bolsistas PET, pois os antigos bolsistas eram alunos do Curso Especial de Bacharelado em Agronomia com Ênfase em Agroecologia e Sistemas Rurais Sustentáveis do PRONERA(Programa Nacional de Educação na Reforma Agrária). O PRONERAé uma iniciativa do Incra (Instituto Nacional de Colonização e Reforma Agrária) que tem por objetivo fomentar parcerias com instituições de ensino públicas para a elevação de escolaridade e formação de jovens e adultos das áreas de reforma agrária, seguindo os princípios da Educação do Campo e da Pedagogia da Alternância. O Curso Especial de Bacharelado em Agronomia com Ênfase em Agroecologia e Sistemas Rurais Sustentáveis teve início em 2009 e foi concluído em 2016, com a formatura de 48 estudantes de assentamentos rurais de todo o Estado de São Paulo. Por este motivo, a grande maioria dos membros atuais são calouros ou nos anos iniciais de seus respectivos cursos, conferindo um perfil menos experiente na agroecologia. Entretanto, isto não significa menos dedicação ou participação nas atividades já iniciadas. Durante o período em que a pesquisa foi realizada, pode-se notar um grande interesse por parte dos novos membros em conhecer a história do grupo e se apropriar das narrativas e atividades já consolidadas como ponto de partida para a construção de sua própria identidade. 


\section{Atividades desenvolvidas e as políticas públicas}

Verificou-se uma grande diversidade de políticas públicas como fontes de recursos financeiros que são acessados pelo Núcleo de Agroecologia Apetê Caapuã. De modo a garantir uma melhor contextualização dos resultados, segue uma breve descrição dos editais vinculados à política de fomento à agroecologia, bem como de apoio à extensão universitária.

\section{Edital MDA/SAF/CNPq 058/2010}

Primeiro edital de Núcleo acessado pelo Apetê Caapuã, a construção deste edital foi realizada de forma participativa com os membros do Comitê de Agroecologia do Conselho Nacional de Desenvolvimento Rural Sustentável (Condraf) e visavam atender três critérios obrigatórios: articulação entre os profissionais da universidade e o território local em iniciativas de extensão rural baseados nos princípios da agroecologia; participação de alunos em caráter inter e multidisciplinar; promover a produção científica a partir dos trabalhos gerados nos núcleos (BRASIL, 2010).

Foram apoiados neste edital 52 projetos distribuídos em 20 unidades da federação. Foram beneficiados 33.346 agricultores, 1.086 professores e pesquisadores, 3.260 estudantes e técnicos (CAVALCANTI, 2015).

Apesar das instituições elegíveis serem apenas as de ensino superior públicas, o estabelecimento de parcerias com organizações nãogovernamentais, instituições de ensino médio, secretarias municipais e estaduais, organizações de agricultores apontam a eficácia do edital enquanto mecanismo de promoção de articulações e disseminação de conhecimento e metodologias.

Com o fomento do edital, o Núcleo Apetê Caapuã conseguiu articular uma série de ações em conjunto com os agricultores familiares da região da Bacia Hidrográfica do Rio Sorocaba - Médio Tietê (municípios de Sorocaba, Araçoiaba da Serra, Ibiúna, Iperó, Itapetininga, Porto Feliz, Salto de Pirapora e São Roque). Foi possível a aquisição de equipamentos, bolsas de dedicação exclusiva para vinte alunos de graduação e três de pósgraduação, articulou-se oficinas de sistematização de experiências de base agroecológica, bem como o diagnóstico e registo junto aos agricultores. O projeto possibilitou a ampliação e consolidação da atuação do Núcleo em seu território, fomentando atividades de ATER juntos aos assentados e agricultores familiares, fortalecendo os processos de transição agroecológica já em andamento ou incentivando o processo. Importante destacar a adoção de metodologias participativas em todos os processos, tanto dentro da própria dinâmica do grupo, quanto no trabalho junto aos agricultores, reforçando os princípios da agroecologia presentes na PLANAPO (Plano Nacional de Agroecologia e Produção Orgânica) (BRASIL, 2013) e na própria PNATER (Política Nacional de Assistência Técnica e Extensão Rural).

Segundo o relatório de execução entregue ao final do edital para prestação de contas, os resultados alcançados contemplaram os três critérios obrigatórios iniciais. Destaca-se a produção de uma cartilha e folders sobre transição agroecológica, além da articulação de dois Fóruns Paulistas de Agroecologia, reunindo 400 participantes, entre agricultores, técnicos e estudantes. Outro resultado importante foi a promoção de um curso de capacitação em agroecologia, com carga horária de 120 horas, para três turmas de 25 docentes, totalizando 75 participantes, dos cursos técnicos de Agropecuária, Agroecologia e Agroindústria do Centro Estadual de Educação Tecnológica Paula Souza - Etecs, de 13 diferentes cidades (Piedade, Jundiaí, Bebedouro, Itapetininga, Iguape, Sorocaba, Taquarivaí, Teodoro Sampaio, Rancharia, Presidente Prudente, Presidente Venceslau, Itu e São Paulo), alocadas em mais de quatro distintas regiões do estado de São Paulo. Portanto, há um alcance territorial importante das ações do núcleo, promovendo a disseminação do conhecimento agroecológico. Além disso, o apoio na consolidação de duas Organizações de Controle Social - OCS, em parceria com dois grupos de assentados. Isto ressalta a importância da ação do núcleo enquanto facilitador e promotor de espaços e oportunidades de fortalecimento da comercialização e integração campo-cidade.

\section{Chamada MCTI/MAPA/MDA/MEC/MPA/CNPq $\mathbf{N}^{\circ}$}

\section{1/2013}

Com o sucesso das ações apoiadas pelo edital anterior, outros órgãos do governo federal somam recursos para a construção da chamada no $81 / 2013$. Os principais objetivos são a implantação ou manutenção de um Núcleo de Estudo em Agroecologia ou de um Núcleo de Pesquisa Aplicada em Pesca e Aquicultura, ou implantação de um Centro Vocacional Tecnológico ou, ainda, a criação de uma Rede de Núcleos de Estudo em Agroecologia.

Com a consolidação do NAAC com o edital anterior, o projeto submetido nesta ocasião visava ampliar o território de ação do grupo, bem como promover a articulação da Caravana Agroecológica Regional como atividade preparatória ao III Encontro Nacional de Agroecologia em Juazeiro-BA 
no ano de 2014. A caravana promoveu visitas às famílias de agricultores parceiras do núcleo possibilitando aos participantes conhecimento e tecnologia de como lidar com desafios econômicos, sociais, políticos e de manejo de agroecossistemas. Uma das bases teóricas que marcam as caravanas é a metodologia campesino a campesino, baseada na solidariedade e intercâmbio entre os próprios agricultores, em uma proposta emancipadora de educação popular visando o desenvolvimento rural sustentável e endógeno (GONZÁLEZ, 2008).

Com este novo edital, o grupo pode avançar no apoio à criação de novas OCS (Organização de Controle Social) na região, bem como a assessoria a grupos de agricultores no acesso ao mercado institucional por meio do PAA (Programa de Aquisição de Alimentos). Além disso, auxiliou no processo de criação do CSA (Comunidade que Sustenta a Agricultura), onde há uma rede de consumidores apoiando a produção de um grupo de agricultores por meio da aquisição de cestas semanais de hortaliças e frutas. Outro processo fortalecido pelo edital foi a consolidação da Feira Agroecológica, possibilitando o incremento de renda dos agricultores participantes.

A partir deste novo projeto, foi possível consolidar a participação de membros do Núcleo em Fóruns e Conselhos tais como o Conselho de Segurança Alimentar (municipal, regional e estadual), o Conselho Municipal de Agricultura, Pecuária e Abastecimento, o Fórum de Agricultura Familiar da Região de Sorocaba, também possibilitou a ampla atuação do Núcleo no fortalecimento de grupos e organizações sociais.

Um importante avanço na organização interna do grupo, propiciado pelo edital foi o fortalecimento dos grupos de estudos. Por meio destes grupos, houve o aprofundamento dos estudos nos diversos temas relacionados à agroecologia e desenvolvimento rural, resultando em 42 publicações das ações do projeto.

Um ponto negativo ressaltado foi a disponibilização de sete bolsas do tipo EXP-C para agentes de ATER de dedicação exclusiva. Apesar de que as bolsas poderiam ser disponibilizadas para técnicos formados, o baixo valor dificultava a permanência e dedicação dos mesmos ao projeto.

Sendo assim, o Núcleo consolidou ainda mais sua identidade como espaço de referência na promoção da Agroecologia e de sistemas de produção de base ecológica reconhecida por instituições de ensino técnico e superior, setor público, terceiro setor, agricultores familiares, comunidade quilombola e assentados da região de Sorocaba.

\section{ProExt - Programa de Extensão Universitária}

Criado em 2003, o ProExt (Programa de Extensão Universitária) era o maior programa interministerial do governo até 2014. Por meio do Ministério da Educação (MEC), Instituições de Educação Superior recebem recursos para execução de ações de extensão universitária com ênfase na inclusão social e subsídio para o desenvolvimento de políticas públicas. Os temas desenvolvidos pelo programa são os mais variados, desde erradicação do trabalho infantil até educação ambiental e apoio ao desenvolvimento comunitário.

A partir do Edital $n^{\circ} 05 \mathrm{MEC} / \mathrm{SESu}$ de 2010 , o Ministério do Desenvolvimento Agrário firma parceria com o MEC, disponibilizando recursos no apoio a atividades da "Linha Temática 6: Desenvolvimento Agrário", cujo subtemas são: apoio à agricultura familiar (como definido na Lei $\left.n^{\circ} 11.326\right)$ objetivando a transição agroecológica para sistemas de produção de base ecológica; capacitação de técnicos das entidades de assistência técnica e extensão rural em manejo ecológico de solos; formação de docentes, técnicos e discentes em agricultura familiar e agroecologia; sistematização de experiências inovadoras em extensão rural junto a agricultura familiar; formação continuada de docentes de extensão rural de instituições de ensino superior e médio (BRASIL, 2010).

Neste contexto, inúmeras instituições de ensino puderam financiar suas atividades ligadas à agroecologia e agricultura familiar. Apesar do ProExt não ser uma política pública específica para o apoio aos Núcleos de Estudos em Agroecologia, muitos grupos ligados à universidade puderam se beneficiar destes recursos e promover atividades de ensino, pesquisa e, principalmente extensão, em agroecologia.

Portanto, desde 2010 o ProExt tem se mostrado uma alternativa interessante de financiamento de atividades de ensino, pesquisa e extensão em agroecologia, possibilitando a manutenção de inúmeras iniciativas ligadas às universidades públicas e instituições de ensino superior, como o Apetê Caapuã.

Como o acesso a esta política se deu ao mesmo tempo que o edital MDA/ SAF/CNPq 058/2010, as ações desenvolvidas no âmbito do ProExt foram complementares. Ressalta-se a importância desta complementariedade, pois possibilitou a soma de esforços e recursos em prol de objetivos comuns, característica rara em termos de políticas públicas.

Apesar da importância desta política pública no incentivo às atividades 
de extensão universitária, não apenas na agroecologia, mas também nas demais áreas, não foram lançados novos editais nos últimos dois anos Infelizmente, a extensão universitária que já é historicamente negligenciada nas universidades fica ainda mais fragilizada com a descontinuidade destes tipos de políticas

\section{PET - Programa de Educação Tutorial}

O PET (Programa de Educação Tutorial) é um programa do MEC instituído pela Lei 11.180/2005 e regulamentado pelas Portarias $n^{0} 3.385 / 2005$, $n^{\circ}$ $1.632 / 2006 \mathrm{e} \mathrm{n}^{\mathrm{o}} 1.046 / 2007$. O programa tem como objetivo fomentar grupos de aprendizagem tutorial por meio de concessão de bolsas a estudantes de graduação e professores tutores, sendo imprescindível o princípio da indissociabilidade entre ensino, pesquisa e extensão, além da educação tutorial. Apesar do grupo não ter um prazo determinado de existência, as bolsas são concedidas até que o aluno termine a graduação e, ao tutor, um prazo máximo de seis anos, renováveis mediante submissão a um edital interno.

O Edital MEC/SESu/SECAD n09/2010 foi dividido em lotes, sendo que cada lote previa um número de grupos a serem apoiados e as características obrigatórias a serem contempladas. Além disso, havia a criação de uma categoria especial de grupo PET chamado "PET/Conexões de saberes", voltados a estudantes de comunidades populares, de modo a ampliar a relação entre a universidade e os moradores de espaços populares, aprofundar a formação dos jovens universitários de origem popular como pesquisadores e extensionistas e estimular a formação de novas lideranças capazes de articular competência acadêmica com compromisso social (MEC, 2010).

É neste contexto que o Apetê Caapuã foi aprovado, sendo constituinte do "Lote H: um novo grupo, por IFES, que envolva exclusivamente estudantes de graduação de comunidades do campo ou quilombolas", assim como outros 35 projetos aprovados. No total, o edital contemplou a criação de 352 novos grupos PET em todo o país.

Naquele momento, o núcleo estava envolvido na coordenação do Curso Especial de Bacharelado em Agronomia com ênfase em Agroecologia e Sistemas Rurais Sustentáveis, promovido pelo PRONERA (Programa Nacional de Educação na Reforma Agrária), sendo que dos 12 bolsistas aprovados, seis eram alunos deste curso especial.

Portanto, o PET apresentou-se como mais uma política pública de apoio a grupos de ensino, pesquisa e extensão ligadas às universidades públicas que beneficiam Grupos de Agroecologia como o próprio Apetê Caapuã. Considerando-se o rol de editais e políticas acessadas, é notável a importância do PET na sustentabilidade a longo prazo do Núcleo. Este programa é a principal fonte de recursos para bolsas de graduação, garantindo a permanência dos membros por tempo suficiente para o desenvolvimento das atividades de ATER. Além disso, o PET possibilita um reconhecimento institucional diferenciado dentro da própria universidade, garantindo maior legitimidade das ações propostas.

\section{PROEX - Pró-Reitoria de Extensão da UFSCar}

A PROEX (Pró-Reitoria de Extensão da UFSCar), segundo informações do site institucional,

“(...) é o setor responsável pela gestão das atividades de extensão realizadas pela UFSCar. A Pró-Reitora de Extensão preside o Conselho de Extensão (CoEx) e a Câmara de Atividades de Extensão (CAE) deste Conselho, e é assessorada em suas tarefas pelo PróReitor de Extensão Adjunto e por coordenadores designados entre os servidores da Universidade.” (BRASIL, 2016).

Anualmente são lançados editais de financiamento de programas e projetos de extensão universitária que visam apoiar iniciativas em todos os campi da universidade. Desde 2009, o Núcleo tem realizado cursos de disseminação do conhecimento agroecológico, por meio de atividades teóricas e práticas com o apoio da PROEX. Tais atividades são conhecidas como "Finais de Semana Agroecológicos" e permitem a realização de oficinas práticas de manejo de áreas com sistemas agroflorestais, preparação de insumos orgânicos, preparados biodinâmicos, entre outros. Além de custear os materiais de consumo e divulgação utilizados, a PROEX financia uma bolsa a aluno de graduação para a realização das atividades.

Portanto, a partir desta contextualização é possível compreender melhor as representações apresentadas a seguir. Quando os membros dos grupos foram indagados sobre as políticas públicas, as respostas não se restringiram apenas aos editais específicos de apoio a Núcleos de Estudos em Agroecologia do MDA/CNPq. Sua avaliação é mais ampla, abrangendo também as políticas descritas acima. 
Feira agroecológica da agricultura familiar na UFSCar Sorocaba

Apesar de estar presente nesta seção do texto, a Feira Agroecológica é uma iniciativa do NAAC que não possui apoio direto de nenhum edital descrito anteriormente. Deste modo, é uma atividade autogestionária e autônoma aqui descrita de modo a complementar a descrição das atividades do grupo no campo da comercialização.

A partir de uma experiência bem-sucedida de comercialização de produtos dos agricultores familiares em um evento de agroecologia organizado pelo Núcleo em 2014 na universidade, identificou-se a grande demanda por produtos orgânicos pela comunidade universitária. Deste modo, a partir do segundo semestre de 2014 iniciou-se a Feira Agroecológica da Agricultura Familiar da UFSCar Sorocaba com a participação de três produtores. A feira ocorre semanalmente às terças-feiras entre $10 \mathrm{~h}$ e $16 \mathrm{~h}, \mathrm{e}$ conta, atualmente, com quatro agricultores, oferecendo hortaliças, doces, compotas, artesanatos, entre outros produtos.

Foram identificadas algumas dificuldades para a sustentabilidade financeira do empreendimento ao longo do processo. Os principais consumidores são professores e funcionários, já que a maioria dos estudantes se alimenta no restaurante universitário, além do campus ser afastado do centro da cidade, dificultando o acesso por parte da comunidade externa. Sendo assim, foram desenvolvidas algumas estratégias para atrair mais público, como a "Música na Feira", além de atividades culturais aliadas à comercialização. Respeitando os princípios da agroecologia e do comércio justo e solidário, se aceita que os feirantes façam a composição de suas bancas com até $30 \%$ (trinta por cento) de produtos de terceiros, desde que mantenham preços acessíveis.

Apesar das dificuldades, avalia-se que a Feira é um importante espaço de sensibilização para a agroecologia, além de ser uma estratégia de comercialização e integração campo-cidade, promovendo a discussão sobre a produção saudável de alimentos em contraposição ao agronegócio. Atualmente, esta iniciativa não possui nenhuma fonte de recursos ligado a projetos ou editais públicos, sendo desenvolvido exclusivamente pelos integrantes do Núcleo, por meio do GT Comercialização.

De modo complementar à feira, foi adotada uma estratégia de comercialização bastante eficiente em que são disponibilizadas cestas semanais de produtos orgânicos mediante pagamento adiantado. Esta estratégia não é recente, mas no Brasil não é muito difundida. De modo geral, os consumidores se organizam em Grupos de Consumo, visando encurtar a cadeia de abastecimento, incentivando relações mais diretas na cadeia comercial, estreitando laços entre os produtores e consumidores (INSTITUTO KAIRÓS, 2013). A organização das cestas contribui para o pagamento de um preço mais justo aos produtores e mais acessível aos consumidores, favorecendo a diminuição dos impactos ambientais, como a emissão de poluentes no transporte.

Atualmente, a Cesta Apetê é composta por oito itens de produtos e, o grupo de consumo conta com a participação de vinte e duas pessoas entre alunos, professores e funcionários da universidade. Estas cestas são entregues semanalmente no mesmo dia e local da Feira descrita anteriormente.

\section{Percepções e avaliação das atividades desenvolvidas pela rede} sociotécnica do Núcleo

No questionário aplicado, uma das questões era: "Cite, em sua opinião, quais as principais atividades desenvolvidas pelo grupo". Todas as respostas abordaram a ATER como meio de fortalecimento da agricultura familiar e das famílias assentadas da região, bem como a própria extensão universitária como as principais atividades desenvolvidas. Citam, ainda a ações de integração campo-cidade, como a Feira Agroecológica e as oficinas de capacitação e dias de campo, como pode ser ilustrada pela fala de um dos entrevistados:

Extensão e pesquisa em agroecologia de maneira que não apenas alunos possam ser abarcados/beneficiados, mas também agricultores familiares, assentados/acampados e a sociedade como um todo. Além disso, desenvolve diálogos e atividades com a comunidade acadêmica, agricultores e outros interessados para disseminar conhecimento sobre agroecologia e sua relação com a formação política (entrevistado, novembro de 2016).

Quando questionados qual a importância das políticas públicas (como os editais do CNPq, PET, ProExt) para o desenvolvimento das atividades descritas anteriormente, todos as respostas foram bastante positivas. Em uma avaliação quantitativa, considerando zero a pior nota e cinco a nota mais alta, a média atingida foi de 4,7. Portanto, na percepção do grupo, as políticas públicas de fomento apresentam uma importância grande. 
Ao serem questionados sobre qual a avaliação que fazem das políticas de fomento, utilizando-se o mesmo critério quantitativo, o resultado obtido foi uma média de 3,7. Portanto, apesar do grupo entender a importância das políticas, sua avaliação é bastante crítica, como ilustra a fala a seguir:

[...] os editais são muito bons para o desenvolvimento das atividades e para o fortalecimento do Núcleo, entretanto a duração é muito curta para dar conta do processo de transição agroecológica, que é um processo de longa duração, além disso, os editais têm exigências excessivas (ex. 081 curso EAD). $O$ montante de recursos também é muito pequeno para dar conta das demandas e exigências. Ademais o montante para bolsas não permite que tenhamos bolsistas de nível técnico e com maior disponibilidade para se dedicar ao núcleo (entrevistado, dezembro de 2016).

Ao aprofundar a análise, surgem duas questões centrais em relação ao financiamento público. A primeira é a disponibilidade de bolsas que permitem a dedicação de estudantes de graduação e pós-graduação, além de profissionais de ATER no desenvolvimento das atividades, uma vez que as mesmas junto aos agricultores demandam planejamento, sistematização que, sem tal financiamento, seriam inviáveis. Outro ponto de destaque são os custos que as atividades de campo demandam. Os recursos financeiros das fontes públicas permitem a viabilização de transporte, tanto dos técnicos quanto dos agricultores nas atividades de ATER, além da aquisição de equipamentos, ferramentas e insumos como, por exemplo, no edital MDA/ $\mathrm{SAF} / \mathrm{CNPq}$ 058/2010 onde foram realizadas sistematizações de áreas modelo de SAF (Sistemas Agroflorestais), desenvolvimento de curso de formação a professores de instituições técnicas.

A partir da chamada MCTI/MAPA/MDA/MEC/MPA/CNPq No 81/2013, percebe-se uma maior integração das ações do núcleo com o contexto regional e estadual, já que foi possível a mobilização da Caravana na região, mas também a preparação para a Caravana Agroecológica e Cultural rumo ao Vale do Ribeira em maio de 2016, uma realização da Rede de Núcleos de Agroecologia da Região Sudeste (R-NEA) e da Articulação Paulista de Agroecologia (rede APA) por meio do Projeto Comboio Agroecológico Sudeste - apoiado, também, pela Chamada Pública do Edital 81/2013. O Núcleo Apetê Caapuã teve papel importante na organização desta Caravana na região e no estado, cedendo bolsistas, mantendo a articulação da rede de atores, facilitando visitas técnicas, além de garantir a participação dos agricultores.

Um dos critérios utilizados pelos membros durante a avaliação foi a capacidade dos programas em fomentar adequadamente o processo de transição agroecológica. Apesar da percepção positiva apresentada pelo grupo, umas das críticas mais recorrentes foi o curto prazo e a quantidade de exigências (atividades e burocracia) dos editais. Considerando-se que as atividades de ATER agroecológica exigem um tempo maior, pois são participativas e requerem maior envolvimento e dedicação de todos os envolvidos, os prazos estipulados pelos editais não são suficientes, na visão dos entrevistados. Até o momento, os editais e programas ocorreram de modo consecutivo, permitindo a continuidade das ações sem interrupções. Entretanto, como não há garantias futuras de que essa coincidência temporal persista, os entrevistados apontam negativamente a duração curta que cada edital propõe, especialmente considerando-se o volume de exigências de resultados, como o edital 081/2013 que obrigava a realização de um curso presencial e outro EAD (Ensino à Distância) sobre agroecologia. Com relação à burocracia, as principais queixas são em relação à execução financeira dos projetos, uma vez que os recursos são repassados de diferentes maneiras para o Núcleo. Por exemplo, os recursos do ProExt são direcionados para o "bolo" da universidade e, posteriormente, acessado pelo professor coordenador através de um sistema específico de compras da instituição, atrasando consideravelmente a dinâmica de aquisição de equipamentos e insumos para as atividades. Já o CNPq apresenta uma dinâmica mais flexível e ágil para a execução financeira, sendo melhor avaliada pelos membros. Frequentemente, o prazo de execução dos projetos se encerra e o recurso ainda não consegue ser utilizado por conta destes entraves burocráticos. Outro ponto crítico é a dificuldade de custeio de diárias para agricultores participarem das atividades, inclusive dentro da própria universidade. Tendo como princípio da construção do conhecimento agroecológico os processos metodológicos participativos, a ausência de recursos financeiros que permitam o deslocamento e participação dos agricultores é bastante negativo.

Cabe, ainda, ressaltar que em todo o percurso da pesquisa ficou evidente a dinâmica de atuação integrativa e gestão horizontalizada do núcleo na execução das atividades. Em determinado momento, isto se mostrou como um desafio à pesquisa, pois exigiu mais atenção do pesquisador na 
identificação das diferentes políticas, uma vez que uma mesma atividade acabava sendo fomentada por mais de uma fonte. No momento das entrevistas era necessário pontuar as diferentes políticas a fim de evitar generalizações.

Ao sistematizar as respostas dos questionários e das entrevistas, foram identificados três grandes grupos de percepções relacionadas à avaliação das políticas públicas de fomento aos NEAs. O primeiro grupo enfatiza o termo Desenvolvimento, articulando as palavras Atividade e Recurso como mais conectados. Tal resultado é concordante com as falas dos entrevistados, já que em sua visão, as políticas propiciam recursos financeiros para o desenvolvimento das atividades do Núcleo, especialmente junto aos agricultores. Isso fica evidente na fala de um dos membros: "essencial pois garante uma melhor qualidade no desenvolvimento dos projetos" (entrevistado, novembro de 2016). O segundo grupo conecta os termos Importância, Fomento e Campo. Novamente, a conexão entre os termos evidencia não só o discurso, mas também as práticas do grupo, uma vez que são realizadas inúmeras atividades de campo junto aos agricultores e assentados da região, de modo a integrar a pesquisa à extensão universitária, outros termos também relacionados neste grupo. Além disso, o próprio curso do PRONERA evidencia a concepção do Núcleo sobre a integração com os movimentos sociais e a responsabilidade social da pesquisa acadêmica. Novamente, tal representação pode ser ilustrada por meio de uma das falas:

Fomentar os núcleos de agroecologia possibilita, através do fortalecimento da agroecologia como rede, gerar um instrumento de justiça social ao aproximar o campo com a cidade, o campo com a universidade e o campo com a produção saudável e soberana. (Entrevistado, dezembro de 2016).

O terceiro e último grupo conecta os termos Importante, Núcleo, Agroecologia e Público. Este grupo evidencia a concepção do Apetê Caapuã em que as políticas de fomento têm o papel importante de aproximar o público geral da agroecologia, de modo a sensibilizá-los para a crise ambiental e social promovido pelo agronegócio. Outra fala é bastante simbólica da representação que o grupo tem: "Uma necessidade para divulgação e entendimento acerca do tema na sociedade" (entrevistado, dezembro de 2016).

Considerando-se que houve uma renovação da maioria dos bolsistas do grupo, é interessante notar as percepções que os membros possuem sobre as atividades desenvolvidas, já que poucos participaram efetivamente dos projetos desenvolvidos. De modo geral, o grupo compreende a importância das políticas no desenvolvimento das atividades, especialmente as atividades relacionadas aos agricultores, consoantes com a concepção de integração entre pesquisa, ensino e extensão universitária. Tal concepção fica evidente se considerarmos o projeto PET/Conexões de saberes, que possibilitou não só a manutenção institucional do grupo, como também a integração e manutenção por meio de bolsas de alunos oriundos de comunidades rurais.

Segundo Jovchelovitch (2008), ao mesclar as experiências, cria-se continuamente a experiência constituinte da realidade de todos, ou seja, a atuação coletiva dos indivíduos proporciona a base estruturante das representações sociais do grupo. Neste sentido, apesar dos membros do grupo serem recém-chegados, a sua inserção nas atividades prévias e o resgate constante do histórico de atividades proporciona o espaço potencial necessário para a socialização dos significados (JOVCHELOVITCH, 2008).

Portanto, na percepção do Núcleo, as políticas públicas são meios de fomentar as atividades consideradas fundamentais para o desenvolvimento da agroecologia no território de atuação do grupo. Cabe ressaltar que a falta destes recursos não implica, necessariamente, que as atividades deixam de ser realizadas, uma vez que o senso de comprometimento e militância de seus membros são superiores à limitação financeira. Entretanto, a todo momento o grupo enfatiza ser fundamental a continuidade do financiamento público dos NEAs, já que as atividades desenvolvidas até então só foram possíveis por meio destes recursos.

\section{Conclusões}

O estudo possibilitou a identificação de diversos instrumentos oriundos das políticas públicas de fomento a agroecologia, seja de modo específico como o Edital MDA/SAF/CNPq 058/2010 e Chamada MCTI/MAPA/MDA/ MEC/MPA/CNPq No 81/2013 que visam o apoio específico aos Núcleos de Estudos em Agroecologia, como o ProExt, ProEX e PET, iniciativas ligadas ao Ministério da Educação que fomentam atividades de extensão universitária e ensino tutorial, promovendo a construção e socialização de conhecimento agroecológico. Para o Núcleo de Agroecologia Apetê Caapuã, essas políticas são fundamentais, tanto para a profissionalização no campo acadêmico, como para atuação na extensão rural junto aos agricultores. 
Como principais pontos negativos são destacados o curto prazo dos projetos, já que o processo de transição agroecológica demanda uma dedicação de tempo maior, tendo em vista seu caráter participativo, e a burocracia na execução financeira dos projetos, inviabilizando o uso do recurso em tempo hábil, além das dificuldades no custeio da participação de agricultores nas atividades, como pagamento de diárias e transporte.

Considerando-se os resultados obtidos, pode-se concluir que os editais específicos do CNPq foram importantes para o fomento das atividades de ATER (Caravana Agroecológica, sistematização de iniciativas de transição agroecológica no território, formação de professores de instituições de ensino técnico em agroecologia, oficinas de formação nos assentamentos, entre outros) e para a produção acadêmica do grupo no período em que estiveram vigentes (cartilhas, artigos em anais de congressos de agroecologia). Entretanto, essas políticas não oferecem sustentabilidade financeira ao núcleo no longo prazo como o Programa de Educação Tutorial que concede bolsas de longa duração a docentes e alunos de graduação, permitindo que não haja descontinuidade do trabalho no apoio à transição agroecológico. Deste modo, apesar dos programas ligados ao Ministério da Educação não serem específicos para implantação e manutenção de Núcleos de Estudos em Agroecologia, eles proporcionam uma segurança institucional e financeira que permite a sustentabilidade do grupo na falta dos editais específicos.

Além disso, verificou-se outras atividades fomentadas pelo grupo que não dependem diretamente de recursos de projetos como a Feira Agroecológica e o programa de Cestas Apetê. Ambas são ações de apoio à comercialização e fomento aos agricultores da região que incentivam a permanência na terra e dão sentido às atividades de ATER descritas anteriormente. Deste modo, o Núcleo busca atuar ao longo de toda a cadeia, desde o apoio à produção agroecológica até a busca por modos de comercialização mais justos e solidários.

Portanto, as políticas avaliadas potencializam umas às outras, formando uma rede de fomento e apoio às atividades do núcleo que são imprescindíveis para a sobrevivência do mesmo e das ações junto às comunidades. Esta é uma experiência singular importante, pois demonstra a importância de projetos de caráter interinstitucional que articulem as diferentes políticas públicas que incidem sobre o mesmo público alvo, potencializando o recurso público. Sendo assim, é fundamental a continuidade dos NEAs como política pública de fomento à agroecologia nos territórios. Entretanto esse cenário é muito incerto e, essa incerteza foi colocada explicitamente no fechamento do
MDA (Ministério do Desenvolvimento Agrário), não havendo perspectiva futura de manutenção dos NEAs. No final de 2016 foi lançada a Chamada MCTIC/MAPA/MEC/SAF-CASA CIVIL/CNPq N 21/2016 que, com recursos insuficientes, selecionou para manutenção somente 32 núcleos de um conjunto de demanda maior, levou a diminuição do número de projetos selecionados e a redução do montante do orçamento por projeto. Deste modo a maioria dos núcleos encontram-se em dificuldades para manter as atividades em curso e, para abrir novas frentes. Consequentemente poderão ser interrompidas ações prioritárias de apoio aos processos de transição agroecológica das unidades de produção familiar de diferentes regiões do país.

Um aspecto não menos relevante do resultado desta pesquisa é que ela nos proporcionou uma reflexão crítica da realidade vivenciada e vinculadas as atividades desenvolvidas no âmbito da operacionalização dos projetos, a partir da análise sociológica que corrobora com a sistematização fina da experiência do núcleo possibilitou efetuar a reconstrução, o ordenamento histórico e a interpretação crítica desta experiência em si, do ponto de vista dos atores e parceiros, facilitando a identificação das dificuldades, fragilidades, potencialidades e funcionamento do núcleo. Essa dinâmica quando compartilhada com o grupo cria um ambiente de aprendizagem mútua que possibilita redirecionar as ações do projeto, realimentar as ações de pesquisa e subsidiar políticas públicas que contribuam para o desenvolvimento rural sustentável.

\section{Referências}

ABRAMOVAY, Ricardo. A rede, os nós, as teias - Tecnologias Alternativas na Agricultura. Revista de Administração Pública - $\mathrm{n}^{\circ} 6$, 2000:159-177, novembro/dezembro. Disponível em: http://www.econ.fea. usp.br/abramovay/artigos_cientificos/2000/A_rede_os_nos.pdf

ABREU, L. S. de A construção da relação social com o Meio Ambiente entre agricultores familiares da Mata Attântica brasileira. Embrapa Meio Ambiente, Jaguariúna/SP, 2005, ISBN 85-85771-34-8, Págs: 1-176

BENSADON, L.S. Tecendo projetos políticos: a trajetória da articulação nacional de agroecologia. Dissertação (Mestrado em Ciências Sociais em Desenvolvimento, Agricultura e Sociedade). Instituto de Ciências Humanas 
e Sociais, Universidade Federal Rural do Rio de Janeiro, Rio de Janeiro, 2016.

BRASIL, Ministério do Desenvolvimento Agrário (BR). Edital MDA/SAF/ CNPq no 058/2010. Brasília; 2010.

. Ministério da Educação (BR). Edital MEC/SESu n⿳005/2010. Brasília; 2010.

Ministério do Desenvolvimento Agrário. Plano Nacional de Agroecologia e Produção Orgânica. 2013. Disponível em: $<$ http://www. mda.gov.br/sitemda/sites/sitemda/files/user_img_19/BrasilAgroecologico Baixar.pdf>. Acesso em: 18 nov. 2016.

. Ministério da Saúde (BR). Conselho Nacional de Saúde. Diretrizes e normas regulamentadoras de pesquisa envolvendo seres humanos: Resolução no 466/12. Brasília (DF); 2012.

. Universidade Federal de São Carlos. Pró-reitoria de Extensão da Ufscar. Pró-Reitoria de Extensão da UFSCar. 2016. Disponível em:

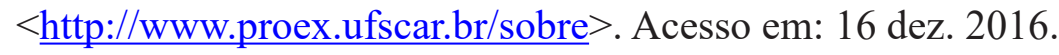

CASTELLS, Manuel. A sociedade em rede. In: A era da informação: economia, sociedade e cultura. Vol. 1. S. Paulo, Paz e Terra, 2003. $7^{\mathrm{a}}$ ed. revista e atualizada.

CAVALCANTI, D.C. Avaliação de Resultados de projetos apoiados pelo Dater por meio do edital MDA/SAF/CNPq $n^{\circ}$ 058/2010, Chamada 2 In: Pesquisa e Extensão para a Agricultura Familiar no âmbito da Política Nacional de Assistência Técnica e Extensão Rural. Ministério do Desenvolvimento Agrário, Brasília-DF, 2015.

FURQUIM, T.W. Encontro nacional de Grupos de Agroecologia (ENGA): dos primórdios à contemporaneidade. Trabalho de Conclusão de Curso (Bacharel em Gestão Ambiental). Setor Litoral, Universidade Federal do Paraná, Matinhos, 2014.
GLIESSMAN, S.R. Agroecologia - processos ecológicos em agricultura sustentável. $3^{\text {a }}$ ed. Porto Alegre. Ed. UFRGS, 2005.

GONZÁLEZ, Argelio. El surgimiento: raíces mayas, ramas mexicanas, frutos nicaraguenses. In: HOLT-GIMÉNEZ, Eric. Campesino a campesino: voces de latinoamerica, movimiento campesino a campesino para la agricultura sustentable. Managua, Nicaragua: Simas, 2008. p. 13-62.

GRAZIANO DA SILVA, J. A modernização dolorosa: Estrutura agrária, fronteira agrícola e trabalhadores rurais no Brasil. Rio de Janeiro, Zahar Editores, 1982.

INSTITUTO KAIRÓS (São Paulo) (Org.). Práticas de comercialização: uma proposta de formação para a economia solidária e a agricultura familiar. São Paulo: Instituto Kairós, 2013. 159 p. Disponível em: $<\underline{\text { http:// }}$ institutokairos.net/wp-content/uploads/2014/02/Kairos-Praticas-deComercializacao.pdf $>$. Acesso em: 03 abr. 2017.

JOVCHELOVITCH, Sandra. Vivendo a vida com os outros: intersubjetividade, espaço público e representações sociais. In: GUARESCHI, Pedrinho A.; JOVCHELOVITCH, Sandra (Org.). Textos em Representações Sociais. 10. ed. Petrópolis, RJ: Editora Vozes, 2008. p. 63-85.

LATOUR, Bruno. Le métier de chercheur. Regard d'un anthopologue. Paris, Inra, 1995.

MELLAZO, G. C. A percepção ambiental e educação ambiental: uma reflexão sobre as relações interpessoais e ambientais no espaço urbano. Olhares \& Trilhas, Uberlândia, ano VI, n. 6, p. 45- 51, 2005.

OKAMOTO, J. Percepção ambiental e comportamento. São Paulo: Editora Mackenzie, 2002.

PACHECO, E.; SILVA, H. P. Compromissos epistemológicos do conceito de percepção ambiental. 2006. Disponível em: < http://www.ivtrj.net/ sapis/2006/pdf/EserPacheco.pdf> .

Acesso em: 20 jul. 2017. 
PETERSEN, Paulo; SÓGLIO, Fabio dal; CAPORAL, Franciso Roberto. A construção de uma ciência a serviço do campesinato: trajetória, desafios e perspectivas da Agroecologia nas instituições científico-acadêmicas brasileiras. In: PETERSEN, Paulo (Org.). Agricultura familiar camponesa na construção do futuro. Rio de Janeiro: As-pta, 2009. p. 85-103.

RADCLIFFE-BROWN, A. R. Structure \& function in primitive society. Londres: Cohen \& West, 1952.

REGA BRASIL (Brasil). Os Grupos de Agroecologia. 2016. Disponível em: $<$ https://regabrasil.wordpress.com/> . Acesso em: 10 nov. 2016.

RIBEIRO, L. M. O papel das representações sociais na educação ambiental. 2003. Dissertação (Mestrado em Educação) - Pontifícia Universidade Católica, Rio de Janeiro, 2003

RODRIGUES, M. et. al. A Percepção Ambiental Como Instrumento de Apoio na Gestão e na Formulação de Políticas Públicas Ambientais in: Saúde Soc. São Paulo, v.21, supl.3, p.96-110, 2012.

ROSA. J.S.V. et al. Tecendo redes entre educação, pesquisa e extensão agroecológicas: a experiência do Núcleo Apetê-Caapuã. Cadernos de Agroecologia, Vol. 9, nº4, Anais do Agroecol, Dourados-MS, 2014.

SIMÕES, E. A. Q.; TIEDEMANN, K. B. Psicologia da percepção. São Paulo: EPU, 1985. v. 10, n. 2 